\title{
Experimental Investigation of Wind Augmenter For Miniature Horizontal Axis Wind Turbine
}

\author{
Authors \\ N.Yogi Manash Reddy ${ }^{1}$, Dr.M.Manzoor Hussain ${ }^{2}$, K.Vamshi Krishna ${ }^{3}$, \\ P.Avinash Reddy ${ }^{4}$, A.Manikanta Reddy ${ }^{5}$ \\ ${ }^{1}$ Asst.Prof. MVSREC, Hyderabad \\ ${ }^{2}$ Prof. JNTU Hyderabad \\ ${ }^{3,4,5}$ Student MVSREC, Hyderabad \\ Email-yogi.manash@gmail.com
}

\begin{abstract}
:
The main idea of this paper is to enhance the performance of a horizontal axis wind turbine using a novel structure developed with a purpose to accelerate the airflow incident on the turbine blades. A micro wind turbine is fabricated with an adjustable pitch control. And the structure is developed using aerodynamic properties providing smooth passage of air with minimum level of turbulence and surface losses. The micro wind turbine is tested with different structural combination namely: with contractor and diffuser, contractor alone and a bare turbine. After conducting tests in a controlled environment with the help of a wind tunnel arrangement it has been observed that there is a significant improvement in the coefficient of power $\left(C_{p}\right)$. The performance characteristics are plotted and the results are concluded. The findings in this experiment manifest that the novel structure improves the performance of the micro wind turbine.
\end{abstract}

\section{INTRODUCTION}

Climate change has become a reality now. Burning of fossil fuels for power generation contributes significantly to the rising $\mathrm{CO}_{2}$ levels in our atmosphere. This urges us to change the way we derive he power. That should be emission free and cost effective. Renewable energy like wind has its limitations and problems. The following is an attempt to miniaturize the use of wind turbines by channeling the driving fuel which is the wind. In this paper we attempt to solve the following problems: miniaturizing the use of wind turbines for power generation in urban areas, improving the conditions for power generation in such built areas. These micro wind turbines need less maintenance and are quite in operation. This technology can also be employed on rural areas and less fortunate parts of the world where still there is no grid connectivity.

The micro wind turbine with novel structure solves the above problems. It does so by concentrating the flow incident on the turbine blade which is otherwise not possible. The fundamental mechanism involved in this is the mass flow rate $(\dot{\mathrm{m}})$ is increased in the rotor region and the flow is accelerated while reducing the wake rotation downstream of the turbine. The brimmed structure at the end of the diffuser is responsible for creating a low pressure region which drives out the air leaving the turbine blades with minimal wake generation. This reduces the drag due to the wake. Thus this becomes critical in drawing in and out the air entering and leaving the rotor respectively. This is cogently explained by gentlemen in the experiment [2][3]. Experiments are carried out on such kind of turbines and are appreciated. This work is different from previously carried out tests. Under controlled environment the velocity $(\mathrm{V})$ from the wind tunnel is measured by using an anemometer and the power $(\mathrm{P})$ generated from the turbine is directly calculated from the generator connected to the rotor of the micro wind turbine without interfering with the experimental conditions. 
Theoretical power co-efficient $\left(\mathrm{C}_{\mathrm{p}}\right)$ is calculated and is compared with experimental data. Experiment is carried out at different angle of incidences and angle of attacks $(\alpha)$ with different combinations of the nozzle and diffuser (novel structure). As the average density variation of atmosphere is assumed to be constant and the area of the rotor (A) and tower height imply more cost for energy the free stream velocity of the air incident is increased by using the novel structure.

$$
\mathrm{P}=1 / 2 * \mathrm{c}_{\mathrm{p}}{ }^{*} \rho^{*} \mathrm{~A} * \mathrm{v}{ }^{3} \ldots \ldots
$$

\section{EXPERIMENTAL SETUP}

The setup consists of detachable contractor and diffuser arrangement along with the bare turbine. It consists of three detachable blades with a constant width of $25 \mathrm{~mm}$. The length of the nozzle and diffuser are $100 \mathrm{~mm}$ with a hub radius of $210 \mathrm{~mm}$ and the inlet and exit radii are $280 \mathrm{~mm}$ and the height of the brim $10 \mathrm{~mm}$. Clearance is maintained as $2 \mathrm{~mm}$ between the blades and the structure. The conical structure is fabricated with a $12^{\circ}$ angle outwards in both nozzle and diffuser [3]. The whole setup is flanged and tested using a wind tunnel. The turbine is tested at different speeds $5 \mathrm{~m} / \mathrm{s}, 6 \mathrm{~m} / \mathrm{s}, 7 \mathrm{~m} / \mathrm{s}, 8 \mathrm{~m} / \mathrm{s}$ etc. with nozzle and diffuser, with only nozzle, with diffuser only and the bare turbine tests are carried out at the speeds and the results are plotted as $\mathrm{P}$ (power) on $\mathrm{y}$-axis and different structural combinations on $\mathrm{x}$ axis at a certain velocity.

The co-efficient of power $\mathrm{C}_{\mathrm{p}}$ is calculated directly by measuring the equation proposed and developed mathematically by D.SH.AKHMEDOV [1]. The free stream velocity $\left(\mathrm{v}_{\infty}\right)$ is measured using an anemometer. The experiment is carried out in four stages with (a) nozzle and diffuser (b) only nozzle (c) bare turbine. Each part can be removed after the each sub stage. The velocities before and after installation and at the hub are measured using an anemometer. Readings for voltage are taken by making use of a multi-meter and the current in the circuit is measured by using appropriate loading usually a series of LED bulbs are enough. This is one method of measuring the actual power produced. Then $\mathrm{C}_{\mathrm{p}}$ can be found out from the below mentioned formula.

$$
\begin{aligned}
& C_{p}(\beta)=(1+\beta)^{*}\left(1-\beta^{2}\right) / 2 \ldots \ldots \\
& \beta=V_{2} / V_{1}
\end{aligned}
$$

$\mathrm{V}_{1}=$ velocity of wind at the hub

$\mathrm{V}_{2}=$ velocity of the wind at the wake region after setup

The experimental setup of small horizontal axis wind turbine is seen to be generating more power when we use the novel structure arrangement while compared to a bare turbine without any enhancements. It accounted for nearly $66 \%$ more power and is generated when we use the novel structure arrangement.

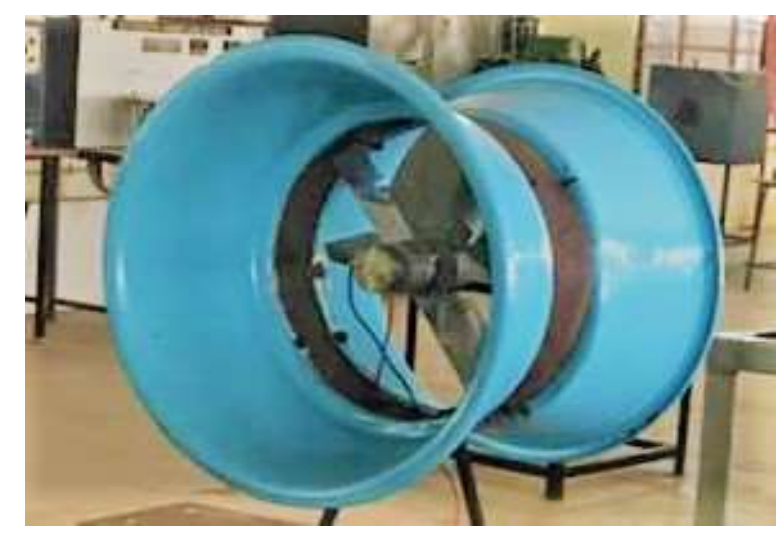

Fig1. Experimental setup of HAWT with convergent-divergent structure

\section{COMPARISON OF BARE WIND TURBINE WITH ONE WITH NOVEL WIND AUGMENTER.}

The experiment is carried out in three steps as stated above (a) Bare turbine

(b) Turbine with convergent structure (nozzle) (c) turbine with both convergent and divergent structure (novel structure). The small turbine has a rotor radius of $103 \mathrm{~mm}$ excluding the clearance at the neck. The structure has the exit diameter of $280 \mathrm{~mm}$ and the length is $100 \mathrm{~mm}$. the height of the brim at the exit is $10 \mathrm{~mm}$. the structure has a contraction or expansion angle of $12^{\circ}$ with diametric ratio of 1.33. The augmentation effect of the convergent divergent wind turbine is significantly higher when compared to a bare turbine. The effect of convergent alone is seen to be greater than the divergent alone. There was a $66 \%$ increase in the power output when compared 
between bare and the novel augmented wind turbine.

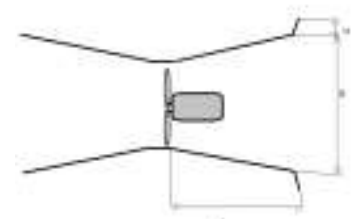

Fig 2 .Typical design of HAWT with nozzle and diffuser

As a result of such setup the velocity at the hub is seen to be increased by $20 \%$ and due to the effect of brim at the exit of the diffuser the performance characteristics of the wind turbine are enhanced by a good amount. The effect of brimmed diffuser is studied by Ohya [2] and Buyung Kosasih [3] and is taken into consideration in this work. As a combined effect of both wind acceleration and the low pressure created at the end of the diffuser the performance of this small wind turbine is observed to be increased. This paper differs from the above works in analyzing and designing a low speed wind turbine which can be operated in urban areas where wind speeds are very low and increase the operating hours of such small wind turbines.

Table.1 $\mathrm{Cp}$ and Power values for various modules with speeds $5,6,7 \& 8 \mathrm{~m} / \mathrm{s}$

\begin{tabular}{|c|c|c|c|}
\hline $\begin{array}{c}\text { Wind Speed, } \\
\mathrm{m} / \mathrm{s}\end{array}$ & Module & $\mathrm{Cp}$ & $\begin{array}{c}\text { Power, } \\
\text { Watts }\end{array}$ \\
\hline \multirow{4}{*}{5} & Bare HAWT & 0.311 & 0.728 \\
\cline { 2 - 4 } & Convergent & 0.359 & 1.381 \\
\cline { 2 - 4 } & $\begin{array}{c}\text { Convergent- } \\
\text { Divergent }\end{array}$ & 0.402 & 1.547 \\
\hline \multirow{4}{*}{6} & Bare HAWT & 0.256 & 0.995 \\
\cline { 2 - 4 } & Convergent & 0.327 & 1.933 \\
\cline { 2 - 4 } & $\begin{array}{c}\text { Convergent- } \\
\text { Divergent }\end{array}$ & 0.362 & 2.14 \\
\hline \multirow{5}{*}{7} & Bare HAWT & 0.225 & 1.389 \\
\cline { 2 - 4 } & Convergent & 0.295 & 2.618 \\
\cline { 2 - 4 } & $\begin{array}{c}\text { Convergent- } \\
\text { Divergent }\end{array}$ & 0.327 & 2.9 \\
\hline \multirow{5}{*}{8} & Bare HAWT & 0.201 & 1.85 \\
\cline { 2 - 4 } & Convergent & 0.268 & 3.4 \\
\cline { 2 - 4 } & Convergent- & 0.298 & 3.781 \\
\hline
\end{tabular}

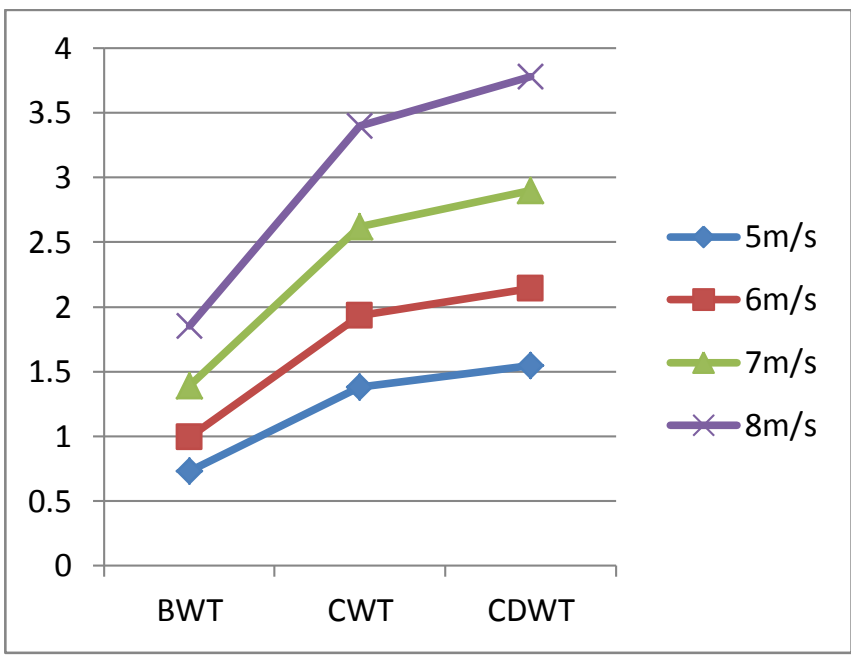

Fig. 3 power (watts) on y-axis and different combinations on $\mathrm{x}$-axis

BWT- bare wind turbine

CWT- convergent wind turbine

CDWT- convergent divergent wind turbine

\section{CONCLUSIONS}

The power generation of the small novel augmented wind turbine is increased by $66 \%$ when compared to bare turbine and the convergent only wind turbine has a $56 \%$ of increase in its power output. The velocity is augmented by $20 \%$ above the level of free stream velocity when we use the novel structure. The coefficient of performance is also increased by $29 \%$ from the bare turbine to the novel augmenter wind turbine at $5 \mathrm{~m} / \mathrm{s}$ and $41 \%$ at 6 and $7 \mathrm{~m} / \mathrm{s}$ respectively.

This concludes that the wind turbine with novel augmenter increases the performance of the wind turbine, and can be employed to design accordingly in low wind speed conditions.

\section{REFERENCES}

1. D.sh. Akhmedov, 2d.i. Eryomin, 3n.i. Yagfarova, 4m.k. Turarbekov, mathematical model to calculate the performance of low power vertical axis wind turbine. International journal of advances in science engineering and technology, issn: 2321-9009 volume- 4, issue-1, jan.-2016.

2. Ohya, y., karasudani, t., sakurai, a., abe, k., inoue, m., 2008. Development of a shrouded wind turbine with flanged 
diffuser. J. Wind eng. And ind. Aero. 96: 524-539.

3. Buyung kosasih, andrea tondelli, experimental study of shrouded microwind turbine, evolving energy-ief international energy congress (iefiec2012).

4. Foreman, k.m., gilbert, b., oman, r.a.,1977. Diffuser augmentation of wind turbines. Solar energy ; 20:305-311. 